\title{
O uso de jogos cognitivos no contexto escolar: contribuições ás funções executivas
}

\author{
Daniela Karine Ramos \\ Universidade Federal de Santa Catarina - Florianópolis - SC - Brasil \\ Natália Lorenzetti da Rocha \\ Universidade Federal de Santa Catarina - Florianópolis - SC - Brasil \\ Kátia Rodrigues \\ Universidade Federal de Santa Catarina - Florianópolis - SC - Brasil \\ Bruna Berger Roisenberg \\ Universidade Federal de Santa Catarina - Florianópolis - SC - Brasil
}

\begin{abstract}
Resumo
O uso de jogos no contexto escolar possibilita o exercício de habilidades cognitivas, emocionais e sociais, pois os jogos favorecem a interação social e a colaboração mútua. Este estudo tem como objetivo analisar os efeitos da intervenção com jogos cognitivos no contexto escolar para a melhora das funções executivas, em especial da atenção, considerando sua importância no processo de aprendizagem. Esse estudo caracterizase como exploratório e descritivo, orientando-se pela abordagem qualitativa. Participaram do estudo seis alunos do Ensino Fundamental, todos do sexo masculino na faixa etária de 7 e 9 anos de idade. Os procedimentos utilizados foram a intervenção com as crianças denominado como atendimento focal, a observação e a sistematização dos registros. A partir deste estudo foi possível constatar a importância dos jogos cognitivos no contexto escolar e como eles podem contribuir significativamente para a melhoria das funções executivas.
\end{abstract}

Palavras-chave: Jogos; escolas; atenção.

\section{The use of cognitive games in the school context: contributions to executive functions}

\begin{abstract}
The use of games in the school context enables the exercise of cognitive, emotional and social skills, since games favor social interaction and mutual collaboration. This study aims to analyze the effects of intervention with cognitive games in the school context to improve executive functions, especially attention, considering its importance in the learning process. This study is characterized as exploratory and descriptive, guided by the qualitative approach. Six primary school students participated, all males aged 7 and 9 years. The procedures used were the intervention with children denominated as focal care, observation and systematization of the records. From this study it was possible to verify the importance of cognitive games in the school context and how they can contribute significantly to the improvement of executive functions.
\end{abstract}

Keywords: Games, Schools, attention.

\section{El uso de juegos cognitivos en el contexto escolar. contribuciones a las funciones ejecutivas}

\section{Resumen}

El uso de juegos en el contexto escolar posibilita el ejercicio de habilidades cognitivas, emocionales y sociales, pues los juegos favorecen la interacción social yla colaboración mutua. Este estudio tiene como objetivo analizar los efectos de la intervención con juegos cognitivos en el contexto escolar para la mejora de las funciones ejecutivas, en especial de la atención, visto su relevancia en el proceso de aprendizaje. Este estudio se caracteriza como exploratorio y descriptivo, orientándose por el abordaje cualitativo. Participaron de ese estudio seis alumnos de la Enseñanza Primaria, todos del sexo masculino en el grupo de edad de 7 y 9 años. Los procedimientos utilizados en el estudio fueron la intervención con los niños denominada como atención focal, la observación yla sistematización de los registros. A partir de este estudio se percibió la relevancia de los juegos cognitivos en el contexto escolar, y como ellos pueden contribuir significativamente para la mejora de las funciones ejecutivas.

Palabras clave: Juegos; Contexto Escolar; atención. 


\section{Introdução}

Os jogos cognitivos são denominados dessa forma por envolverem o uso das habilidades cognitivas para o bom desempenho do jogador, podendo ser do tipo tradicional ou eletrônico. De acordo com Ramos (2013, p. 20),os jogos cognitivos referem-se a "um conjunto de jogos variados que trabalham aspectos cognitivos, propondo a intersecção entre os conceitos de jogos, diversão e cognição". Nesse contexto, a cognição é entendida como "a aquisição, o armazenamento, a transformação e aplicação do conhecimento" (Matlin, 2004, p. 2).

Além do exercício das habilidades cognitivas, o uso de jogos no contexto escolar possibilita o exercício de habilidades emocionais e sociais, uma vez queseu uso favorece a interação social e a colaboração mútua. A utilização de jogos cognitivos implica os jogadores em uma situação de negociação, de conflito e de oposição, devido ao fato deser uma atividade delimitada por regras nas quais a pessoa precisa autorregular seu comportamento e aprender a lidar com a frustração advinda de uma derrota, por exemplo (Ramos, 2014).

Nesse trabalho, compreende-se as habilidades cognitivas como as capacidades que tornam o sujeito competente e Ihe possibilitam que interaja simbolicamente com o meio, incluindo a discriminação de objetos, a identificação e classificação de conceitos, a resolução de problemas e a aplicação de regras,as quais propiciam a estruturação contínua dos processos mentais (Gatti, 1997).

Tendo em vista a problemática das habilidades cognitivas, destacam-se as funções executivas (FE) num conjunto de habilidades que, de forma integrada, permitem ao indivíduo direcionar comportamentos e metas, avaliar a eficiência desses comportamentos, abandonar estratégias ineficientes a favor de outras mais eficientes e solucionar problemas (Malloy-Diniz, Sedo, Fuentes, \& Leite, 2008). As FE referem-se a um termo abrangente que, por sua vez, se relacionam com os processos de controle, permitindo uma integração entre o físico e o cognitivo através de processos de autocontrole, autorregulação e flexibilidade mental (Corbett, Constantino, Hendren, Rocke, \& Ozonoff, 2009; Lent, 2005). Essas funções estão associadas às habilidades necessárias para formular um objetivo, antecipar e planejar, definir metas e executar planos de modo eficiente (Anderson, 2002; Lent, 2005; Pereira, 2010).

Dentre as FE, a atenção é uma habilidade cognitiva muito considerada nos estudos da área, contemporaneamente, a qual está intimamente ligada ao uso dos jogos cognitivos. A atenção envolve a discriminação de um alvo relevante, a sensibilidade perceptual e a redução da interferência dos estímulos distratores (Pessoa, Kastner, \& Ungerleider, 2003). A mesma pode ser classificada de diversos modos, a saber, como voluntária e involuntária (Dalgalarrondo, 2000; Macar, 2001) ou como atenção seletiva, atenção sustentada, atenção alternada e atenção dividida quando se considera o tipo de processamento (Gazzaniga \& Heatherton, 2005; Sternberg \& Dalgalarrondo, 2000). Sendo a aprendizagem resultado da assimilação de informações retidas para uso posterior, é possível presumir o papel fundamental que a atenção desempenha nessa capacidade de retenção de informações relevantes e no armazenamento de dados na memória de longa duração (Ladewig, 2000).

Com base nosautoresque se dedicam à problemática (Adams, 1971; Fitts \& Posner, 1967; Magill, 1989; Schmidt, 1988), existe uma relação positiva entre a facilidade para a realização de qualquer atividade e o quantos e pratica essa atividade. Dentre as diversas modificações, que ocorrem na medida em que praticamos uma atividade com regularidade, estão as reduções na carga dos processos de atenção e a habilidade de perceber e captar informações relevantes à tarefa. Percebe-se que o uso regular dos jogos pode constituir uma prática ou exercício dessa habilidade, influenciando diretamente na melhora desse processo cognitivo. No que tange à essa constatação, evidencia-se que jogadores de videogame possuem um melhor desempenho em uma série de capacidades cognitivas, como atenção, processamento perceptual e funções executivas, quando comparados às pessoas que não jogam videogame (Boot, Kramer, Simons, Fabiani, \& Gratton, 2008; Weinstein, 2010).

Rivero, Querino e Alves (2012) salientam que os jogos eletrônicos apresentam uma rápida sucessão de estímulos visuais ou auditivosos quais os jogadores necessitam focalizar sua atenção. Para obterem sucesso nos jogos, os jogadores precisam sustentar a atenção durante longos períodos de tempo e evitar estímulos distratores. Ademais, precisam gerenciar diversas tarefas, ao mesmo tempo em que necessitam manter a meta central do jogo. Todas essas características, em um ambiente altamente veloz e pouco previsível tornam os jogos ferramentas poderosas no treino da atenção (Rivero\& cols., 2012).

A partir disso considera-se a importância das FE, da atenção e das contribuições do uso dos jogos no contexto escolar para o aprimoramento das habilidades cognitivas, este estudo tem como objetivo analisar os efeitos da intervenção com jogos cognitivos no contexto escolar para a melhora das funções executivas, em especial da atenção.

\section{Método}

\section{Desenho do estudo}

Esse estudo caracteriza-se como exploratório e descritivo, orientando-se pela abordagem qualitativa, pois toma para análise os atendimentos realizados com um grupo de crianças que participaram da atividade de Atendimento Focal, desenvolvida no Colégio de Aplicação da Universidade Federal de Santa Catarina, localizado na cidade de Florianópolis.

\section{Participantes}

Participaram desse estudo seis alunos do Ensino Fundamental (anos iniciais). Todos do sexo masculino na 
faixa etária de 7 e 9 anos de idade comf requência nos atendimentos realizados que variou de 10 a 21 vezes.

Os critérios para inclusão observados foram: estar frequentando regularmente o Ensino Fundamental; ter sido indicado pelo professor para participar do atendimento em função de apresentar alguma dificuldade em relação à atenção; ter o Termo de Consentimento Livre e Esclarecido assinado e o interesse em participar das atividades.

Por envolver crianças, a pesquisa foi submetida e aprovada pelo Comitê de Ética, conforme parecer n. 400.436 e os pais ou responsáveis assinaram o Termo de Livre Consentimento indicando aceitar participar da pesquisa.

\section{Procedimentos}

Os procedimentos utilizados no estudo foram a intervenção com as crianças denominada como atendimento focal, a observação e registros feitos com base nas intervenções e nas entrevistas realizadas com as professoras. Essas entrevistas ocorreram antes e depois da realização dos atendimentos. Inicialmente, a entrevista buscou conhecer e investigar as queixas, dificuldades e aspectos positivos percebidos em sala. Ao final, a entrevista procurou identificar se as professoras observaram mudanças nas crianças em relação à atenção, às funções executivas e à aprendizagem.

\section{Intervenção}

A estrutura do atendimento focal, de acordo Ramos (2014) foi inspirada na estrutura das sessões de terapia cognitiva descrita por Friedberg e McLure (2004), porém volta-se para a atenção, a aprendizagem no contexto escolar e para o atendimento de grupos de 2 a 4 crianças. Cabe ressaltar ainda, que se trata de um atendimento com foco psicopedagógico. A seguir passamos a descrever os procedimentos de intervenção utilizados e sistematizados por Ramos (2014):

a) Registro da atenção: consiste no momento inicial do atendimento, em que os alunos são questionados sobre como percebem a sua capacidade de manter a atenção naquele momento, incentivando a autoavaliação e a percepção de seus estados cognitivos. A partir disso,cada criança pintava um dos cinco smiles que indicam estados de atenção dispostos em uma tira de papel.
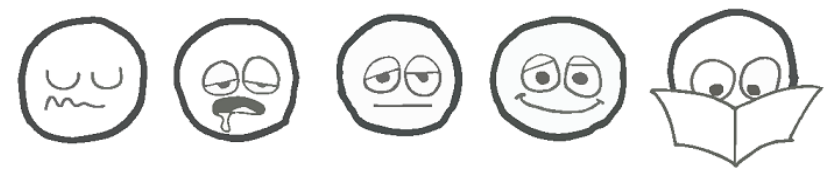

Figura 1. Recurso utilizado para o registro da atenção. Fonte: Ramos (2014). b) Revisão dos desafios da semana: contempla exercícios que são levados para casa a fim de que a criança tivesse ainda mais contato com atividades cognitivas, fora do ambiente escolar. O desafio inclui jogos ou atividades, como por exemplo, sudoku, caça-palavras, palavras cruzadas ou labirintos. Posto isso, nesse momento questionava-se a criança sobre como foi fazer ou resolver os desafios da semana anterior.

c) Estabelecimento da agenda: apesar de haver um planejamento prévio da sessão, nessa etapa, conversa-se com o aluno sobre o que ele gostaria de fazer e acerca do que havia sido planejado. Dessa maneira, a criança era instigada a pensar no que gostaria de jogar, mas também a ceder quando outras crianças querem jogar outras coisas, bem como se acorda acerca do comprometimento que os alunos deveriam ter com as atividades estabelecidas.

d) Intervenção com jogos: desenvolve-se o que foi planejado e acordado, utilizando os jogos, constituindo-se como um momento fundamental de observação e intervenção dos mediadores, uma vez que ocorremas orientações, realiza-se a mediação de conflitos e conduzem-se os procedimentos.

e) Desafios da semana: apresentam-se e explicam-se os desafios que a criança é convidada a fazer e trazer no atendimento seguinte.

f) Feedback: ao final do atendimento conversa-se com as crianças a respeito dos jogos e das atividades realizadas, bem como incentiva-se a descreverem como se sentiram e o que perceberam em relação a sua atenção, no percurso do atendimento. Ademais, durante esse procedimento ocorre a avaliação conjunta de categorias comportamentais contempladas na tabela de reforçamento. Essa tabela compreende quatro blocos, a saber: 1) Atitude (avalia se a criança teve calma, paciência e persistência durante os jogos); 2) Atenção (nos jogos, nas regras e no que é falado pelos colegas e mediador); 3) Compromisso (avalia se a criança fez e trouxe o desafio da semana) e 4) Interação (avalia o relacionamento entre pares e mediador). Essa avaliação era feita com base no uso de smiles de três cores distintas no formato de adesivos que eram colocados na tabela: vermelho, amarelo e verde, assim a criança que tivesse obtido total êxito em determinada categoria ganhava smile verde, a que teve um desempenho mediano smile amarelo e a que precisava melhorar smile vermelho.

Para facilitar a compreensão das etapas do atendimento e a sua sequência foi utilizado um relógio, conforme se avançava nos procedimentos mudava-se o ponteiro do relógio. Esses atendimentos foram realizados uma vez por semana, no contraturno das atividades escolares regulares, por um período de aproximadamente 6 meses. 
Tabela 1. Caracterização inicial a partir da sistematização dos comportamentos registrados.

\begin{tabular}{|c|c|c|c|c|c|c|}
\hline & \multicolumn{6}{|c|}{ Comportamentosregistrados } \\
\hline & Desatenção & $\begin{array}{c}\text { Pouca } \\
\text { persistência }\end{array}$ & $\begin{array}{l}\text { Dificuldade na } \\
\text { interação social }\end{array}$ & $\begin{array}{l}\text { Dificuldade de } \\
\text { cumprir metas }\end{array}$ & $\begin{array}{l}\text { Intolerância à } \\
\text { frustração }\end{array}$ & $\begin{array}{l}\text { Impaciência ou } \\
\text { irritação }\end{array}$ \\
\hline P1 & $\Delta \infty \Delta$ & & $\diamond \diamond$ & $\diamond$ & & \\
\hline P2 & $\diamond$ & $\diamond \diamond$ & & $\diamond$ & $\Delta \diamond$ & $\diamond$ \\
\hline P3 & $\Delta \infty$ & & $\Delta$ & $\otimes$ & $\Delta \diamond$ & \\
\hline P4 & $\diamond$ & & $\Delta \Delta \Delta$ & $\Delta \infty \Delta$ & $\Delta$ & $\Delta \infty \Delta$ \\
\hline P5 & $\Delta \infty$ & $\otimes \diamond$ & $\diamond$ & $\infty$ & $\Delta \diamond$ & $\otimes \diamond$ \\
\hline P6 & $\Delta \infty \Delta$ & $\otimes$ & $\diamond$ & $\diamond$ & & \\
\hline
\end{tabular}

Nota. $\diamond=$ pouco frequente; $\diamond \diamond=$ frequente; $\diamond \diamond \diamond=$ muito frequente; $E m$ branco= não registrado.

\section{Materiais e instrumentos}

Este estudo pautou-se fundamentalmente na análise dos registros das observações feitas a partir dos atendimentos realizados. O formulário para o registro era on-line e foi estruturado com base nos procedimentos utilizados durante os atendimentos.

Os jogos cognitivos foram os principais recursos utilizados durante os atendimentos. Esses se davam em um formato mais tradicional -como jogos de memória, quebra-cabeça, dominó e damas e em um formato eletrônico, por meio do uso da Escola do Cérebro. A Escola do Cérebro, mediante jogos eletrônicos como tangran, tetris e genius, possibilitou o exercício dashabilidades cognitivas como a atenção, resolução de problemas e memória.

\section{Análise dos dados}

As observações realizadas durante as intervenções foram registradas e analisadas de modo que fosse possível identificar as interações e comportamentos que pudessem ser tomados como indicadores de envolvimento e exercício das habilidades cognitivas.

As entrevistas realizadas com as professoras foram transcritas e analisadas de acordo com a perspectiva da análise de conteúdo (Bardin, 1977), utilizando procedimentos sistemáticos de descrição do conteúdo das entrevistas e observações, definido indicadores para permitir a inferência de conhecimentos. Com base em Bardin(1977), na pré-análise realizamos a leitura flutuante dos registros, procurando identificar as categorias e indicadores e preparação do material para análise, na exploração do material organizamos o conteúdo e fizemos sua codificação com base nos indicadores, para então, proceder ao tratamento dos resultados, o que possibilitou a ocorrência deinferências e interpretações.

\section{Resultados e Discussão}

Os resultados são analisados tomando como referência a estrutura do atendimento focal, procurando destacar as observações e registros realizados a fim de evidenciar as mudanças, manifestadas nos comportamentos e no desempenho das crianças participantes.

$\mathrm{O}$ atendimento focal, no contexto da presente pesquisa, caracterizou-se como uma atividade extra classe oferecida como uma estratégia compensatória com o propósito de garantir melhores condições para a aprendizagem das crianças. Nesse sentido, o atendimento contribuiu para cumprir a função compensatória da escola, a qual visa contribuir para atenuar os efeitos das desigualdades e preparar o sujeito para se defender e atuar no cenário social (Pérez Gómez, 1998). Os objetivos da intervenção, a metodologia e os recursos utilizados podem inspirar atendimentos realizados em contextos clínicos de psicologia que intervenham em situações relacionadas a dificuldades de aprendizagem, bem como na atuação de psicopedagogos ou psicólogos escolares.

Os primeiros atendimentos realizados juntamente com as entrevistas iniciais feitas com as professoras permitiram sistematizar as principais características das crianças participantes. No quadro abaixo, são indicados os comportamentos manifestos nos primeiros atendimentos e as características descritas pelas professoras, nas entrevistas.

\section{Verificação da atenção}

O primeiro procedimento, previsto na estrutura do atendimento focal, era a verificação da atenção. Com base nos registros feitos pelos mediadores foi constatado que o nível de atenção mais considerado pelas crianças foi o último, ou seja, o nível mais elevado de atenção. Durante esse momento, cada uma das crianças deveria justificar tal 
resposta tendo em vista o momento em sala de aula que a levou a responder de determinada forma. Procurava-se, ainda, que essa exercitasse aauto-percepção. Observou-se que no início muitos alunos acabavam não entendendo ou não sabendo justificar o motivo de ter indicado o nível mais elevado. Entretanto, ao longo dos atendimentos, as crianças foram compreendendo melhor o que era a atenção e o quanto aquele era um espaço no qual poderiam se expressar da maneira como realmente se percebiam, uma vez que não tinha o objetivo de emitir um juízo de valor ou punir. Assim, foi possível observar maior capacidade de argumentação dos participantes para justificar o motivo de ter escolhido determinado nível.

A percepção é uma função cognitiva fundamental para a autorregulação, pois se refere à capacidade de associar informações a memória para formar conceitos sobre o mundo e nós mesmos, constituindo-se como base para que possamos orientar nosso comportamento (Lent, 2005).

Para ilustrar o momento inicial dos atendimentos de avaliação da atenção e o exercício da percepção sobre o estado de atenção, exemplificamos o caso do P5, em que inúmeras vezes dizia que seu nível de atenção era 5 (mais alto), contudo não conseguia justificar esse fato. Talvez pela sua postura de repetidas vezes buscar o elogio e o reconhecimento por parte dos mediadores, demonstrava certa incerteza quando apontava para este nível. A partir das constantes explicações e mediações, P5 passou a se expressar com mais facilidade e indicar outros níveis de atenção mais condizentes com os comportamentos expressos no atendimento. Assim, ao indicar outros níveis, em especial o 4, passou a demonstrar melhor capacidade de autopercepção.

De modo geral, a maioria das crianças passou a avaliar o nível de atenção de forma mais coerente, buscando relações com o que havia acontecido ou com a forma que agiam dentro da sala de aula. Desse modo, algumas relacionavam a falta de atenção, dentro da sala de aula, a eventos internos ou externos ao contexto escolar. P2, por exemplo, relatava que se distraía quando colegas próximos conversavam. Já P3, relatou diversas vezes que estava com sono e cansado devido ao fato de ter ido dormir muito tarde na noite anterior ou pelo fato de ter dormido na casa de um parente.

Comumente, apesar das dificuldades iniciais no tocante a essa etapa do Atendimento Focal, os resultados obtidos perante as análises dos registros, revelam que as crianças começaram a se autoperceber de forma mais coerente, uma vez que identificaram fatores que poderiam ser distratores ou servir de auxílio para a manutenção da sua atenção na sala de aula.

Esse aspecto é fundamental, pois como Lent (2005) indica, a atenção consiste em um mecanismo seletivo que separa os estímulos relevantes dos irrelevantes, criando melhores condições de percepção aos seres humanos no tocante aos estímulos relevantes. Assim, ao auxiliar as crianças a identificar o que é um estímulo irrelevante que leva a distração, podemos contribuir para o aprimoramento da capacidade de manter a atenção nas atividades escolares em sala de aula. Esse aspecto contribui para que os participantes pudessem compreender melhor o que os cerca e, a partir disso, pensar em estratégias para se distanciar dos estímulos que lhes causavam distração, criar estratégias e se aproximar de situações favoráveis à manutenção da atenção.

\section{Desafios da semana}

Os desafios da semana configuravam-se como exercícios a serem feitos em casa que estimulavam, principalmente, a concentração e a resolução de problemas de forma divertida e lúdica.

O momento da revisão da tarefa de casa contribuiu para reforçar sua importância e permitir o diálogo sobre o interesse, sentimentos e dificuldades da criança (Friedberg \& McLure, 2004). Além disso, essa etapa permitia a discussão sobre como foi fazer os desafios, o que revelou que, para algumas crianças, este era um momento interativo entre a família, uma vez queos pais ou irmãos acabavam se envolvendo e ajudando na resolução do desafio.

Haja vista a análise dos registros, foi possível notar que o comprometimento com o desafio da semana, em geral, foi baixo, comparando o número de vezes em que as crianças trouxeram e não trouxeram o desafio proposto. Além disso, pode-se observar ainda que no começo dos atendimentos a prática de não trazer era bem mais constante. Após os primeiros dois meses de intervenção os participantes começaram a trazer o desafio da semana de forma mais assídua. Os motivos alegados para não trazerem os desafios completos, frequentemente, era ter esquecido de fazer ou trazer e perder a folha. P3, por exemplo, quando não trazia se explicava dizendo que sua mãe havia se esquecido de colocar na mochila.

Quando as crianças faziam o desafio da semana, algumas tinham como hábito desenhar e colorir a folha. P2, por exemplo, expressava muita satisfação ao mostrar os desenhos que havia feito. P6 quando trazia, sempre ressaltava a ajuda dos pais na resolução do desafio e manifestava muito alegria por conta disso. Já P1, em grande parte das vezes, comentava que o desafio da semana tinha sido fácil e que sua mãe pouco o ajudou já que não era tão necessário. Em síntese, os desafios que demandavam maior concentração, como o sudoku, eram os que as crianças mais achavam complicado e os preferidos eram os labirintos.

\section{Estabelecimento da agenda}

O Estabelecimento da Agenda foi experienciado pelas crianças como um misto de ansiedade - por querer falar ou impor o que queriam jogar -, escuta e compreensão, visto que também era o momento de ouvir o colega e o mediador sobre a vontade deles. Na maioria das vezes, cada participante expressava o que queria jogar e os acordos eram feitos, levando em consideração o tempo que tinham para jogar todos os jogos que as crianças e os mediadores que- 
riam. Em geral, dois jogos ou desafios eram jogados, assim o tempo era dividido nesses dois momentos.

O estabelecimento da agenda, assim como a interação nos jogos coletivos, pressupunha o exercício das funções executivas, isso porque segundo Lent (2005) elas se manifestam no universo social, regidas pela qualidade e pela adequação das relações interpessoais.

Esporadicamente, certas crianças tiveram dificuldade para aceitar o que o outro queria jogar. P4, por exemplo, sempre queria jogar jogos eletrônicos no tablet e nas vezes em que isso não era possível, demonstrava tristeza e expressava comportamentos mais agressivos (gritando, jogando seu boné no chão, etc). Nesse caso, a mediação e melhor compreensão das regras ao longo dos atendimentos contribuíram para que nos últimos atendimentos essas manifestações mais agressivas diminuíssem.

P2 também expressava certa frustração e tristeza quando os jogos que queria jogar não eram escolhidos para o atendimento. Diante disso, verbalizava que os jogos escoIhidos pelos amigos e mediador eram "chatos e sem graça". Contudo, quando começava a jogar, tinha momentos de alegria e verbalizava "estou gostando". Nessas circunstâncias, durante a mediação, foi sinalizado para a criança que esta manifestava comportamentos contraditórios entre gostar ou não dos jogos e que precisava aceitar e se dispor a experimentar, algo antes de manifestar seu julgamento.

Já P3 quando se sentia contrariado em vários momentos do atendimento, principalmente, passava a se comunicar com voz e palavras mais infantilizadas. Outros participantes como P1 e P6 eram mais tímidos para explicitar o que gostariam de jogar. $\mathrm{P} 1$, por exemplo, sempre foi muito compreensivo e acabava aceitando os jogos que os outros queriam em detrimento aos seus. Aos poucos P1 e P6 foram se soltando e colocando com mais facilidade sua vontade perante o grupo.

\section{Intervenção com jogos}

Ao longo dos atendimentos muitos jogos e desafios cognitivos foram utilizados. Trabalhou-se com diversos formatos: eletrônico, de tabuleiro, de desafio individual, de desafio coletivo, entre outros, uma vez que nossa intervenção com jogos se baseia no conceito de que jogo cognitivo é um conjunto de jogos variados que proporcionam diversão, ao mesmo tempo em que exercitam a cognição humana (Ramos, Rocha, Luz, Silvestrin, \& Schmaedech, 2014).

Nos atendimentos, foram utilizados jogos individuais, como de encaixe ("Pirâmide Finlandesa", "T" e "Cubo Anguis"), de lógica ("Torre de Hanói" e "Hora do Rush"), de pregos e laçada ("Tio peixe" e "Tablita") e jogos coletivos como de tabuleiro e oposição. Os jogos individuais requeriam a atenção concentrada, o uso da memória de trabalho, o planejamento de estratégias, sua execução e avaliação, a persistência na tentativa de solução e o autocontrole.

Quanto aos jogos coletivos utilizados, como: Uno, Dominó, Pega Varetas, 60 segundos e Jogo da Memória, os mesmos envolviam a interação entre mais de uma autoregulação e o autocontrole na interação com o outro. Diamond e Lee (2011) relacionam as funções executivas à flexibilidade, ao autocontrole e à disciplina, bem como ao planejamento das ações que se contrapõe a respostas impulsivas e à manutenção do foco.

Nesse sentido, os jogos utilizados muitas vezes exigem que ocorra um planejamento para a ação, uma tomada de decisão e o exercício da resolução de problemas. O autocontrole e a paciência são exercitados durante esses jogos, uma vez que as crianças precisam esperar sua vez para jogar, necessitam lidar com a frustração de perder ou com a alegria de ganhar. O jogo pode ajudar a lidar com a frustração, pois acaba promovendo um "fracasso divertido" (McGonigal, 2012), o que possibilidade desenvolver maior tolerância.

Em relação aos jogos eletrônicos utilizou-se a Escola do Cérebro que integra a uma base de dados jogos cognitivos eletrônicos, como Genius, Tangran e Tetris, permitindo que a criança jogue e acompanhe sua evolução e desempenho. Os jogos cognitivos eletrônicos "envolvem um conteúdo, uma estrutura e uma mecânica de jogo que favorecem o exercício de habilidades cognitivas, que se tornam fundamentais a evolução do desempenho no jogo" (Ramos, 2013, p. 23).

Resguardando o objetivo de exercitar as habilidades cognitivas, todos os jogos, sejam individuais, coletivos ou eletrônicos, foram utilizados de maneira combinada durante os atendimentos. E o tipo de jogo mais pedido, principalmen-
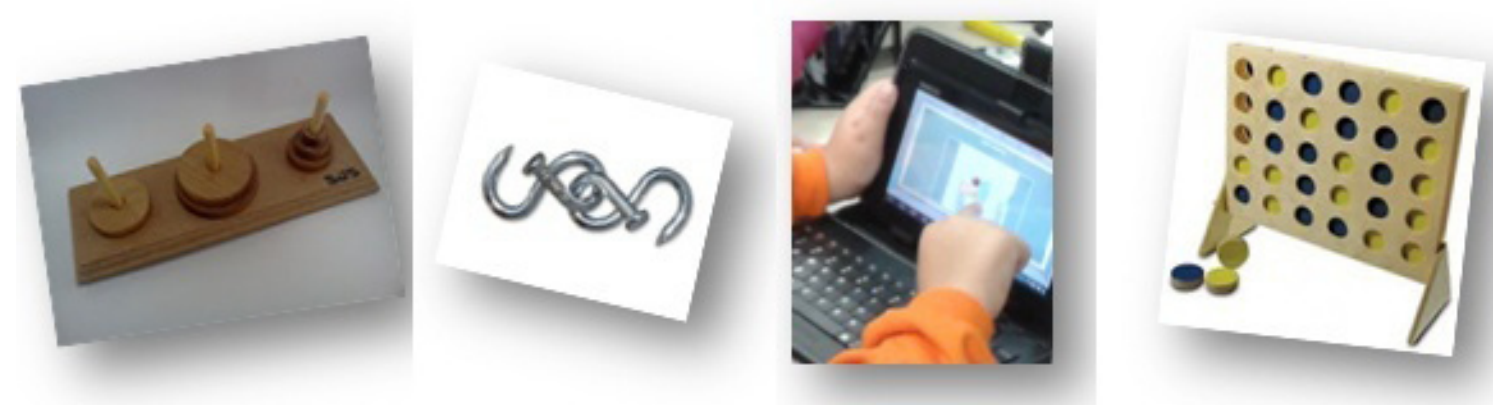

Figura 2. Jogos cognitivos utilizados nos atendimentos. 
te, nos primeiros atendimentos era a Escola do Cérebro. As crianças ansiavam por ter contato com o tablet e, consequentemente, com a interatividade do meio eletrônico. Este fato pode ser ilustrado através das atitudes do P4 que era uma das crianças que raramente gostava de jogar algo que não tivesse ligação com jogos eletrônicos.

Outros jogos que despertavam muito interesse dos alunos eram "Uno" e "Pega Varetas". Os jogos coletivos, apesar de criarem um clima de competição possibilitavam também manifestações de comportamentos cooperativos, como a explicação adicional para um amigo que não havia entendido as regras. Esses comportamentos referem-se ao que McGonigal denomina como pró-sociais e é reforçado por Prensky (2010), o qual defende que as crianças aprendem com os jogos a "colaborar efetivamente uma com as outras" (p.37).

\section{Feedback}

A finalização dos atendimentos ocorria por meio do feedback, momento em que os participantes se autoavaliavam e recebiam feedbacks do mediador e das outras crianças participantes. Dessa maneira, durante essa etapa ficavam mais visíveis as evoluções e as dificuldades de cada um, sendo possível pensar em melhorias, firmar acordos ou reforçar comportamentos positivos que repercutissem na aprendizagem e no desenvolvimento das funções executivas.

De acordo com Friedberg e McLure (2004), esse momento do feedback contribui para melhorar a percepção das crianças e a capacidade de expressão. No entanto, esse pode ser um momento crucial para os mediadores por exigir um manejo adequado em relação à autoestima, passividade, insegurança ou relutância em dar um feedback.

Observamos que no início dos encontros os participantes não conseguiam expressar com clareza como avaliavam seu comportamento. Por mais que a tabela utilizada fosse explicativa e ilustrativa, era difícil para as crianças relacionar seus comportamentos durante os atendimentos com os smiles. Foi notável o quanto ao findar dos encontros os alunos passam a se perceber e, consequentemente, se avaliar de maneira mais coerente. Também se notou que o momento do feedback era um dos mais esperados por eles, e durante o atendimento sempre faziam menção a tal etapa. P5, por exemplo, quando era questionado acerca de sua atenção no jogo, sempre dizia que "ia melhorar porque queria smile verde".

O autocontrole também era muito observado nessa etapa visto que algumas crianças possuíam dificuldade de recebercrítica negativa. $\mathrm{P} 4$, nos primeiros atendimentos, reagia com agressividade quando recebia smile amarelo ou vermelho. Nos últimos, começou a aceitar um pouco melhor a crítica, sem expressar comportamento como jogar o boné no chão ou gritar.

Quanto aos feedbacks positivos, havia alunos que eram muito descrentes em si mesmos, e quando recebiam elogios ou retornos positivos ficavam surpresos. Talvez pelo "estigma" de serem vistos como "maus alunos" ou por não terem recebidos retornos tão condizentes com o que expressavam ali no Atendimento Focal. P6, nos primeiros encontros, se avaliava com smile vermelho ou amarelo. Mesmo quando suas atitudes foram merecedoras de um smile verde, parecia duvidar e até demonstrar surpresa quando os colegas e o mediador diziam que ele havia ido muito bem.

Com base no exposto, pode-se intuir que essa etapa fez com que as crianças aprendessem a lidar com a crítica, mas também com os retornos positivos advindos de seu meio. Constatou-se que quando se relaciona o feedbackrecebido pelo meio com a autopercepção da criança em determinada situação, o participante se torna mais ciente do seu comportamento e possui mais chances de melhorar.

\section{Indicativo de melhora no atendimento focal e em sala de aula}

A partir dos registros e as análises, buscamos, com base nas categorias inicialmente utilizadas para caracterizar as crianças, indicar os principais avanços e dificuldades percebidas em cada participante, procurando evidenciar os resultados obtidos com as intervenções. Diferente da tabela inicial, utilizamos o termo autocontrole para evidenciar a diminuição de comportamentos de irritação e impaciências, que em algumas situações eram demonstrados por agressões, e acrescentamos o desempenho nos jogos como um indicador de melhora nas habilidades cognitivas envolvidas.

A partir do quadro, evidenciam-se mudanças em aspectos comportamentais e em indicadores das funções executivas, como no aprimoramento de habilidades importantes para o melhor desempenho nos jogos. Isso por que os jogos "nos dão a oportunidade de aprender e dominar novos desafios e, de modo geral, desenvolver habilidades que podemos repassar a outros jogadores em nossas vidas" (McGonigal, 2012, p. 97). Nesse sentido, P1 passou a manter o foco de atenção por mais tempo, apesar de no momento do feedback ainda apresentar dificuldades para comentar acerca de sua autopercepção. Já em P2 observamos que o mesmo começou a seguir os acordos combinados, não expressando mais vontade de querer trocar de jogo constantemente, e manifestou maior autocontrole ao aceitar a vitória dos colegas. O autocontrole pode ser relacionado, ainda, com a manifestação de mais persistência, menos impulsividade e melhor atenção (Diamond \& Lee, 2011), aspectos que também tiveram melhora em vários participantes.

A fim de melhor esclarecer como constatamos a relevânciae os resultados desses atendimentos, confeccionamos uma tabela para ilustrar a quantidade de atendimentos realizados e número de smiles verdes, amarelos e vermeIhos de cada participante em cada competência (atitude, atenção, compromisso e interação). 
Tabela 2. Indicadores de melhora nos comportamentos observados e registrados.

\begin{tabular}{|c|c|c|c|c|c|c|c|}
\hline & \multicolumn{7}{|c|}{ Comportamentosregistrados } \\
\hline & Desatenção & $\begin{array}{c}\text { Pouca } \\
\text { persistência }\end{array}$ & $\begin{array}{l}\text { Dificuldade na } \\
\text { interação social }\end{array}$ & $\begin{array}{l}\text { Dificuldade de } \\
\text { cumprir metas }\end{array}$ & $\begin{array}{l}\text { Intolerância à } \\
\text { frustração }\end{array}$ & Autocontrole & $\begin{array}{c}\text { Desempenho } \\
\text { nos jogos }\end{array}$ \\
\hline P1 & $\uparrow$ & $\uparrow \uparrow$ & $\uparrow$ & $\uparrow$ & & & $\uparrow$ \\
\hline P2 & & $\uparrow$ & & $\uparrow \uparrow$ & $\uparrow$ & $\uparrow$ & $\uparrow$ \\
\hline P3 & & & $\uparrow$ & & & $\uparrow$ & \\
\hline P4 & $\uparrow \uparrow$ & & $\uparrow$ & & $\uparrow$ & $\uparrow$ & $\uparrow \uparrow$ \\
\hline P5 & $\uparrow \uparrow$ & $\uparrow$ & $\uparrow$ & & $\uparrow$ & $\uparrow$ & $\uparrow$ \\
\hline P6 & $\uparrow$ & $\uparrow$ & & $\uparrow$ & & & $\uparrow$ \\
\hline
\end{tabular}

Nota. $\uparrow \uparrow=$ muita melhora; $\uparrow=$ melhora; $\downarrow=$ piora; Em branco= não foi registrada mudança .

\section{Distribuição da quantidade de carinhas contabilizadas nas tabelas de reforçamento}

Para sistematização e análise desses dados, registramos a partir da tabela de reforçamento o número desmiles verdes da primeira metade da tabela e da segunda metade da tabela para proceder a comparação. Por exemplo, caso tenham sido realizados 14 atendimentos, analisamos quantos smiles verdes no total de todas as competências (atitude, atenção, compromisso e interação) nos primeiros 7 atendimentos e depois a quantidade total nos últimos 7 atendimentos, dessa forma conseguimos observar se as competências melhoraram com o tempo de atendimentos realizados.

No gráfico abaixo sintetizamos os dados analisados nas tabelas de reforçamento.

A partir do gráfico podemos observar que tivemos um aumento no número de smiles verdes recebidos no momento do feedback dos atendimentos, com exceção do sujeito 5.

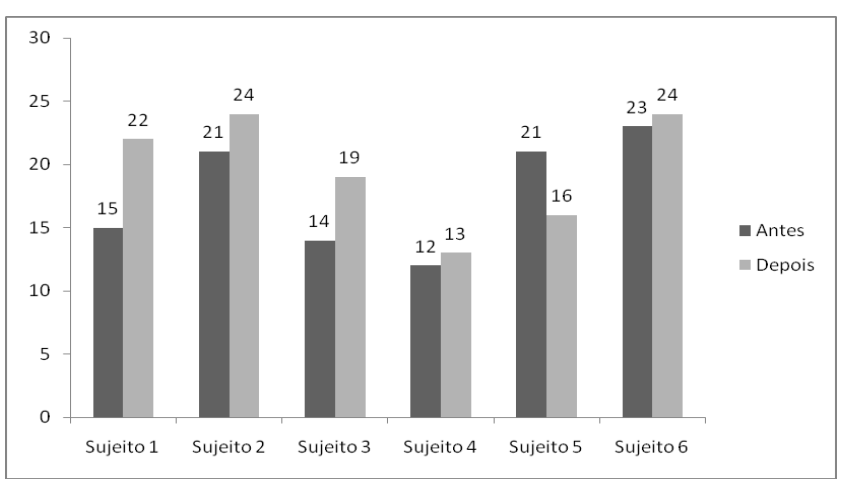

Figura 3. Comparação entre a quantidade de smiles verde na primeira metade dos atendimentos (antes) e na segunda metade (depois).
Os demais, aumentaram o número de smiles verdes ao longo do tempo de intervenção do atendimento focal, demonstrando um maior entendimento das competência sem questão, além de melhora do comportamento nesses quesitos. Esse resultado pode ser tomado com um indicador que reforça as contribuições dos atendimentos no desenvolvimento das habilidades cognitivas.

Apesar de esta pesquisa voltar-se para a análise da evolução percebida nas crianças participantes em relação aos comportamentos observados e registrados ao longo dos atendimentos focais, ao realizar a entrega das devolutivas às professoras, realizou-se uma entrevista para identificar se elas haviam percebido mudanças nos participantes em sala de aula e em relação ao processo de aprendizagem.

Todas as professoras perceberam algum tipo de mudanças nas crianças, com maior ou menor expressividade. Algumas associaram as mesmas às intervenções realizadas no atendimento focal, uma delas chegou a relatar que percebia quando a crianças não tinha participado do atendimento. Segundo a professora de P5 "eu chegava a sentir diferença quando P5 não ia à cognoteca, pois ficava mais desatenta".

Essas mudanças reforçam aquelas percebidas durante o atendimento focal e corroboram com estudos que têm avaliado os efeitos do uso dos jogos para o treinamento da atenção. Um estudo realizado em um contexto muito similar, porém voltado para o uso dos jogos cognitivos digitais em sala de aula, apontou melhoras em relação à capacidade de atenção e à motivação das crianças, bem como um desempenho crescente no jogos e maior autocontrole em sala de aula (Ramos \& Rocha, 2016)

A partir da análise e transcrição dessas entrevistas identificamos, identificou-se que a principal mudança observada e relatada pelas professoras refere-se à melhora na atenção em sala de aula, que era expressa pela evolução na 
Tabela 3. Distribuição da quantidade de carinhas contabilizadas nas tabelas de reforçamento.

\begin{tabular}{ccccccccccccc}
\hline & Atitude & & Atenção & & Compromisso & & Interação \\
\hline P 1 & 9 & 8 & 0 & 8 & 7 & 2 & 9 & 0 & 8 & 12 & 5 & 0 \\
\hline P 2 & 12 & 8 & 1 & 13 & 6 & 2 & 7 & 1 & 12 & 14 & 7 & 0 \\
\hline P 3 & 9 & 5 & 1 & 12 & 3 & 0 & 6 & 2 & 6 & 11 & 3 & 1 \\
\hline P 4 & 9 & 1 & 0 & 8 & 2 & 0 & 1 & 1 & 8 & 7 & 3 & 0 \\
\hline P 5 & 7 & 7 & 0 & 11 & 3 & 0 & 6 & 0 & 8 & 13 & 0 & 1 \\
\hline P 6 & 12 & 6 & 0 & 14 & 4 & 0 & 4 & 1 & 13 & 17 & 0 & 1 \\
\hline
\end{tabular}

compreensão mais fácil do que era para ser feito em sala e na diminuição dos episódios de distração. Essa mudança constatada pelas professoras, no que tange a quatro das crianças participantes, em transcrições como: "se distraia com muita facilidade e se movimentava muito, chegando em alguns momentos a ficar embaixo da mesa, e isso não ocorreu mais tanto" (professora de P5) ou "observei mudanças, passou a se organizar mais em sala de aula, antes não atendia mesmo solicitando e agora consegue responder" (professora de P4).

As mudanças na atenção foram relacionada à melhor organização em sala e dos próprios materiais como. Tal trecho ilustra esta evidência:"antes eu tinha mais preocupação em relação à atenção e à organização dos materiais, uma ordem no grupo não adiantava, tinha que ir na mesa e pedir para ele pegar o caderno... Muitas mudanças em relação a organização dele, mais envolvido nas tarefas e dando conta de pequenas tarefas relacionadas à organização" (professora de P6). Em duas crianças essas mudanças em relação a organização foram relatadas.

A percepção dos professores acerca do desempenho dos participantes pode ser tomado como um indicador para as contribuições do uso dos jogos para o processo de aprendizagem das crianças. Esse indicador foi considerado em outra pesquisa que analisou os benefícios dos jogos cognitivos digitais utilizados em sala de aula. Os resultados do referido estudo foram pautados na entrevista com os professores e indicaram mudanças no tocante à atenção, à capacidade de resolução de problemas e aos comportamentos sociais (Ramos, 2013).

Essas melhoras podem resultar na maior autonomia das crianças e na necessidade de menos auxílio e ajuda. Em nosso estudo esse foi o segundo aspecto mais relatado pelas professoras (observado em três crianças). Além disso, ainda tivemos relatos de maior autocontrole (observado em duas crianças) e maior confiança em si mesmo, o que resultava na maior persistência na realização das atividades (observado em duas crianças). Segundo a professora de P4 "antes se descontrolava mais facilmente, agora se controla mais... ele tinha bastante dificuldade para esperar e isso melhorou".
A análise dos registros realizados e a avaliação das professoras constituem-se fortes indicativos de que o uso de jogos digitais cognitivos nas escolas, seja em atendimentos extra classe ou mesmo como atividades integradas ao currículo, pode contribuir para o exercício dasfunções cognitivas. Essas funções, por sua vez, são fundamentais à aprendizagem e que repercutem sobre o modo como a criança se percebe, na interação com os demais ena motivação para aprender. Tais contribuições reforçam o jogo como um recurso lúdico que pode constituir-se como alternativa pedagógica a fim demelhorar as condições para aprendizagem.

\section{Considerações finais}

A partir deste estudo, destacam-se as contribuições que o Atendimento Focal pode trazer para as crianças em contexto escolar. No quesito de verificação de atenção, vimos que ao longo dos atendimentos, as crianças foram compreendendo melhor o que era a atenção e foram adquirindo uma maior capacidade de argumentação quanto ao que estavam percebendo de si mesmas, identificando fatores que poderiam ser distratores ou servir de auxílio para a manutenção da sua atenção na sala de aula.

Verificou-se que os desafios da semana são importantes para que a criança continue a exercitar suas habilidades cognitivas além do período em que estão no atendimento, e também para que haja um envolvimento familiar nas tarefas da criança. $O$ estabelecimento da agenda, assim como a interação nos jogos coletivos, favoreceu o exercício das funções executivas, em especial, a autorregulação e o autocontrole na interação com o outro, havendo um aumento da qualidade e adequação das relações interpessoais. Os jogos individuais requeriam a atenção concentrada, o uso da memória de trabaIho, o planejamento de estratégias, sua execução e avaliação, a persistência na tentativa de solução e o autocontrole. Os jogos cognitivos eletrônicos também favoreceram o exercício de habilidades cognitivas, que se tornaram fundamentais para a evolução do desempenho no jogo. 
A finalização dos atendimentos, por meio do feedback, tornou visíveis as evoluções e as dificuldades de cada um, sendo possível pensar em melhorias, firmar acordos ou reforçar comportamentos positivos que repercutem na aprendizagem e no desenvolvimento das funções executivas.

Com isto reforça-se a importância do uso dos jogos cognitivos no contexto escolar e como eles podem contribuir significativamente para a melhoria das funções executivas. Ressalta-se, ainda, a importância de que mais estudos sejam feitos nesta área, de forma a abarcar a extensão do quanto os jogos cognitivos podem contribuir para que as funções executivas sejam desenvolvidas.

Apesar das contribuições que puderam ser identificadas, especialmente, nos atendimentos realizados e reforçadas pelos professores na avaliação feita por meio da entrevista, torna-se fundamental avaliar melhor as efetivas mudanças que ocorrem em sala de aula, procurando estabelecer relações entre as intervenções realizadas e seus efeitos sobre o desempenho das crianças nas atividades em sala de aula.

\section{Referências}

Adams, J. A. (1971). A closed-loop theory of motor learning. Journal of motor behavior,3(2), 111-150.

Anderson, P. (2002). Child Neuropsychology: A Journal on Normal and Abnormal Development in Childhood and Adolescence, 8(2).

Bardin, L. (1977). Análise de conteúdo_Lisboa: Editora Edições 70.

Boot, W. R., Kramer, A. F., Simons, D. J. Fabiani, M., \& Gratton, G. (2008). The effects of video game playing on attention, memory, and executive control. Acta Psychologica, 129, 387-398.

Corbett, B. A., Constantine, L. J., Hendren, R., Rocke, D., \& Ozonoff, S. (2009). Examining executive functioning in children with autism spectrum disorder, attention deficit hyperactivity disorder and typical development. Psychiatry Research $\_$166(2-3), 210-222.

Dalgalarrondo P. (2000). Psicopatologia e semiologia dos transtornos mentais. Porto Alegre: Artmed.

Diamond, A., \& Lee, K. (2011). Interventions Shown to Aid Executive Function Development in Children 4 to 12 Years Old. Science, 333(6045), 959-964.

Fitts, P. M. \& Posner, M. I. (1967).Human performance. Monterey, California: Brooks Cole.

Friedberg, R. D. \& Mcclure, J. M. (2004).A prática clínica de terapia cognitiva com crianças e adolescentes. Porto Alegre: Artmed.

Gatti, B. A. (1997). Habilidades cognitivas e competências sociais. Laboratorio Latinoamericano de Evaluación de la calidad de la educación. Santiago: LLECE, OREALC /UNESCO.
Gazzaniga, M. S. \&Heatherton, T. F., (2005).Ciência psicológica. Porto Alegre: Artmed.

Ladewig, I. (2000). A Importância da atenção na aprendizagem de habilidades motoras. Revista Paulista de Educação Física, supl. 3, 62-71.

Lent, R. (2005). Cem bilhões de neurônios: conceitos fundamentais de neurociência. São Paulo: Atheneu.

Macar, R. (2001). Atenção. Em R. Doron, R. \& F. Parot (Orgs.), Dicionário de Psicologia (pp. 88-89). São Paulo: Ática.

Magill, R. A. (1989). Motor learning: concepts and applications (3a. ed.). Dubuque, Wm.C.Brown.

Malloy-Diniz, L. F., Sedo, M., Fuentes, D., \& Leite, W. B. (2008). Neuropsicologia das funções executivas. Em D. Fuentes, L. F. Malloy-Diniz, C. H. P. Camargo, \& R. M. Cosenza (Orgs.), Neuropsicologia: teoria e prática. Porto Alegre: Artmed.

Matlin, M. W. (2004). Psicologia cognitiva(5a. ed.). Rio de Janeiro, RJ: LTC.

McGonical, J. (2012). A realidade em jogo: porque os games nos tornam melhores e como eles podem mudar o mundo. São Paulo: Record.

Pérez Gómez, A. I. (1998). As funções sociais da escola: da reprodução à reconstrução crítica do conhecimento e da experiência. Em J. Gimeno Sacristán \& A. I. Pérez Gómez (Orgs.),Compreender e transformar o ensino (4a. ed., pp. 13-26). Porto Alegre: ArtMed.

Pereira, F. S. (2010). Funções executivas e funcionalidade no envelhecimento normal, comprometimento cognitivo leve e doença de Alzheimer. Tese de Doutorado, Faculdade de Medicina da Universidade de São Paulo, São Paulo, SP, Brasil.

Pessoa, L., Kastner, S., \& Ungerleider, L. G. (2003). Neuroimaging studies of attention: from modulations sensory processing to topdown control. The Journal of Neuroscience, 15 (10), 3990-3998.

Prensky, M. R. (2010). Teaching digital natives: Partnering for real learning. California: Corwin Press.

Ramos, D. K. (2013). Jogos cognitivos eletrônicos: contribuições à aprendizagem no contexto escolar. Ciências \& Cognição, 18, $19-32$.

Ramos, D. K. (2014). Cognoteca: uma alternativa para o exercício de habilidades cognitivas,emocionais e sociais no contexto escolar. Revista FAEEBA, 23(41).

Ramos, D. K., Rocha, N. L., Luz, M. L., Silvestrin, D., \& Schmaedech, D. (2014). O uso de jogos eletrônicos para o exercício das habilidades cognitivas: relato de uma experiência no Ensino Fundamental. Em Anais do X Seminário Jogos Eletrônicos, Educação e Comunicação: Construindo Novas Trilhas. Salvador: UNEB. 
Ramos, D. K. \& Rocha, N. L. (2016). Avaliação do uso de jogos eletrônicos para o aprimoramento das funções executivas no contexto escolar. Revista Psicopedagogia, 33, 133-143.

Rivero, T. S., Querino, E. H. G., \& Alvez, I. S. (2012). Videogame: seu impacto na atenção, percepção e funções executivas. Revista Neuropsicologia Latinoamericana. 4(3), 38-52.

Schmidt, R. A. (1988). Motor and action perspectives on motor behaviour. Advances in psychology, 50, 3-44.
Sternberg, R. J. \& Dalgalarrondo, P. (2000). Psicologiacognitiva. Porto Alegre: Artmed.

Weinstein, A. M. (2010). Computer and video game addiction-a comparison between game users and non-game users. The American Journal of Drugand Alcohol Abuse,36(5), 268- 76.

Recebido em: 16 de março de 2016 Aprovado em: 21 de novembro de 2016

\section{Sobre as autoras}

Daniela Karine Ramos (dadaniela@gmail.com)

Doutora em Educação, Professora do Programa de Pós-Graduação em Educação e do Departamento de Metodologia de Ensino da Universidade Federal de Santa Catarina, Brasil.

Natália Lorenzetti da Rocha (natalialorenzettirocha@gmail.com)

Psicóloga graduada pela Universidade Federal de Santa Catarina, Mestranda pelo Programa de Pós- Graduação em

Psicologia da Universidade Federal de Santa Catarina, Brasil.

Katia Julia Roque Rodrigues (floripakatiarr@gmail.com)

Psicóloga graduada pela Universidade Federal de Santa Catarina, Brasil.

Bruna Berger Roisenberg (brunapc@gmail.com)

Psicóloga graduada pela Universidade Federal de Santa Catarina, Mestranda do programa Mestrado Profissional em Saúde Mental e Atenção Psicossocial da Universidade Federal de Santa Catarina, Brasil. 
